\title{
Taxation Influences upon the Market in Venture Capital Trust Stocks: Theory and Practice
}

\author{
Kevin Holland and Richard H. G. Jackson ${ }^{*}$
}

\begin{abstract}
Individuals investing in a Venture Capital Trust IPO listed on the London Stock Exchange receive a number of conditional tax incentives; the time related nature of the associated conditions can create a 'lock-in effect'. By deriving and testing a model of the value of these incentives we examine how they influence investors' pricing and trading decisions. This paper contributes to the ongoing tax capitalisation debate in three ways: first, in calculating the magnitude of the lock-in effect without reference to underlying shareholder records; second, in adopting a time series approach - in view of the time varying magnitude of the potential lock-in effect - and thereby avoiding control issues involved in cross-sectional analysis of the effects of taxation on pricing; and third, by focusing on changes in the bid-ask spread rather than, for example, mid-price, so reducing the impact of changes in the market value of the instruments under consideration on the analysis. Our results have direct policy implications in suggesting a conflict between the existence of time related conditional tax incentives and the requirement for VCTs to be listed on the London Stock Exchange explicitly in order to promote liquidity in a historically illiquid sector of the market.
\end{abstract}

\footnotetext{
* The authors are, respectively, Professor of Accounting and Taxation, University of Southampton and Associate Professor of Accounting and Finance, University of Exeter. The authors would like to thank the following for their helpful comments and suggestions: Dan Dhaliwal, David Gwilliam, David Knight (of Allendribdge Investment Consultants), Lillian F. Mils, Kaye J. Newberry and Mike Peel; seminar participants at the University of Wales, Aberystwyth, Cardiff University and Birmingham University; and delegates at the British Accounting Association Annual Conference 2004, the American Accounting Association Annual Conference 2004 and the Tax Research Network Annual Conference 2004. The authors would also like to thank a number of Venture Capital Trust advisors, fund managers and market makers for discussions and comment, and Xenia Holstein, Lei Meng and, in particular, Mark Rhodes for their valuable input.
} 


\section{Introduction}

Successive UK governments, like their counterparts in the US, The Netherlands and elsewhere have attempted to use tax-based incentives to correct a perceived market failure in the provision of finance to small, unquoted companies. One such scheme in the UK promotes the use of Venture Capital Trusts (VCTs). An explicit aim of the VCT legislation is the provision of an exit strategy to investors thereby reducing one source of the potential market failure (HM Inland Revenue, 2002). Consequently, VCTs are required to be listed on the London Stock Exchange. We report, however, that the secondary market in VCT shares is characterised by low levels of market liquidity as indicated by typically low trading volumes. This paper examines whether investors' pricing and trading decisions can be explained in terms of tax considerations and, therefore, whether the design the VCT legislation (and associated tax legislation) is a potential source of the low liquidity.

Individuals investing in a VCT IPO receive a number of conditional tax incentives including, most significantly, 'investment relief' - an income tax rebate based on the sum initially invested. To reduce the potential benefits of 'tax avoidance', a repayment or 'clawback' of the rebate can arise if the shares in the VCT are sold within a 'required holding' period (HM Treasury, 2003). This paper derives a model of the present value of the conditional tax incentive during the currency of the required holding period, and then tests empirically a number of predictions about market behaviour based on this model.

The issue of the impact of taxation on asset prices has been subject to considerable academic investigation. There remains, however, a lack of consensus over, in particular, the impact of investor level taxes and share prices - see, for example, Harris and Kemsley (1999), Harris et al. (2001), Collins and Kemsley (2000), Dhaliwal et al. (2003) and Hanlon et al. (2003). This study focuses on the impact of investor level conditional tax incentives and has parallels in the analysis of capital gains tax. In particular, when the taxation of gains is limited to realised gains, shareholders are provided with an incentive to defer the realisation of a gain, i.e., a 'lock-in effect' is created (Stiglitz, 2000). ${ }^{1}$ Klein (2001) demonstrates that potential sellers of shares with an unrealised gain demand a higher price than they would have done for the shares without any such unrealised gain - in order to cover the capital gains tax liability which would crystallize on sale. Examining price reaction around an unexpected reduction in the length of the capital gains holding period, Blouin et al. (2002) document empirical evidence consistent with Klein (2001). Announcement date abnormal returns were, on average, negative for those (IPO) firms benefiting most from the change. Inconsistent with a tax explanation, however, the losses were reversed almost immediately - in fact, the following day. Earlier work by Landsman and Shackelford (1995) on the RJR Nabisco leveraged buyout confirmed that shareholders with higher unrealised gains demanded higher prices (the authors' access to confidential shareholder records allowing them to observe directly shareholders' unrealised or locked-in gains). In order to identify shares trading at an unrealised gain in the absence of access to shareholder

\footnotetext{
${ }^{1}$ Lock-in effects can arise in other tax settings, for example, under corporation tax settings in the context of disposal of assets on which capital or investment allowances have been granted; or in the context of the decision as to whether or not to continue trading where there exist past trading taxation losses which are yet to be utilised.
} 
records, Blouin et al. (2002) follow Reese (1998) in focusing on recent IPOs and assume no change in the initial shareholding distribution.

Our results confirm the existence of a lock-in effect, consistent with findings of low trading volumes, and have direct policy relevance on two aspects. First, the resulting disincentive to trade reduces liquidity, thereby potentially reducing VCTs' ability to attract funding and increasing their cost of capital; and second, the lock-in effect inhibits VCT investors from re-investing in more profitable activities, thus creating a welfare loss (Stiglitz, 2000). The results may be summarized as follows. First, VCT bid-ask spreads evolve over time in a way consistent with investment relief being capitalised, and the bid-ask spread increases as the present value of the investment relief increases. As the present value increases over time, VCT shareholders require an increasingly higher price if they are to sell within the required holding period and, thus, forfeit their investment relief. Potential secondary market purchasers, however, are not entitled to investment relief and are, therefore, only willing to pay a price that is independent of any investment relief consideration. ${ }^{2}$ Second, VCT spreads fall significantly and the number of customer bargains increases significantly following the end of the required holding period, consistent with the cessation of the lock-in effect. Third, spread is greater for VCTs with a three-year as opposed to a five-year required holding period - consistent with the present value of the investment relief being higher the shorter the holding period. And fourth, VCT spread and volume traded are, respectively, greater than and less than spread and volume traded for a nonVCT comparator sample - for which comparator sample, in the absence of specific tax incentives, there is no tax-related required holding period. Overall these results are consistent with Landsman and Shackelford (1995), Klein (2001) and Blouin et al. (2002). We argue, however, that they present stronger evidence of a lock-in effect, this being facilitated by the setting for our study.

In addition to its policy relevance, our study contributes to the lock-in literature principally in three respects. First, by calculating the magnitude of the lock-in effect with certainty, yet without reference to underlying shareholder records - which allows examination of a broader sample than would be likely to be available were access to confidential shareholders' records required. Second, in adopting a time series approach - in view of the time varying magnitude of the potential lock-in effect - and thereby avoiding control issues involved in cross-sectional analysis of the effects of taxation on pricing. And third, by focusing on changes in the bid-ask spread rather than, for example, mid-price, so reducing the impact of changes in the market value of the instruments under consideration on the analysis.

The paper proceeds as follows: the next section discusses VCTs, the method of their issue and associated taxation regulation; the third section develops a theoretical model for the valuation of VCT investment relief; the fourth section describes the data, hypothesis and research method; the results are presented and discussed in the fifth section; and the final section concludes.

\footnotetext{
${ }^{2}$ In that the relief is only available to initial subscribers it is similar to the reduced rate of capital gains on qualified small business stock in the US. Guenther and Willenborg (1999) conclude that on the introduction of the reduced rate of capital gains tax the issue price of qualifying stock increased - consistent to a reduction in small business's cost of capital. In focussing on the impact of conditional tax incentives, the public policy issue addressed in this paper differs from that addressed by Guenther and Willenborg (1999).
} 


\section{Legislative and institutional background}

Legislation establishing VCTs was included in the UK Finance Act 1995, and the first VCT was created in November 1995. The term 'trust' is, strictly, a misnomer - since, in order to be approved as VCTs under the Finance Act 1995, they are required to be public limited companies quoted on the London Stock Exchange. Approval under the 1995 Act results in two distinct sets of tax reliefs - shareholder-level reliefs and firmlevel reliefs. Critical to this analysis, shareholder-level reliefs are restricted to private individuals, thereby excluding the possibility that the (rational) marginal shareholder could be a tax-exempt organisation. ${ }^{3}$ The terms of approval are given in S.70, Finance Act 1995, and are primarily concerned with the composition of the assets held by the $\mathrm{VCT}^{4}$, size of holding ${ }^{5}$ and size of companies in which it invests. ${ }^{6}$ The legislation also specifies approved trades, in order to direct investment away from relatively low risk asset-backed investment ventures towards risky activities which may, otherwise, experience difficulty in attracting investment.

The requirement that all VCTs must be quoted on the London Stock Exchange is designed to provide investors with a ready market for assets with typically illiquid underlying investments and thereby reduce the risks associated with unquoted investments. ${ }^{7,8}$ Individual investors may obtain a number of tax reliefs when investing in VCTs. Original subscribers (but not secondary market purchasers) can obtain income tax relief at a rate of 20 percent on the cost of their original investment - referred to as 'investment relief' for the purposes of this paper - conditional upon the shares being held by the individual for a required holding period. This required holding period was originally five years, but was reduced (non-retrospectively) to three years for seasoned and unseasoned issues occurring on or after $6^{\text {th }}$ April 2000. If the shares are disposed of before the expiration of the required holding period a 'clawback' of the income tax occurs, based on the lesser of amount invested or disposal proceeds. Additionally, a subscription to acquire VCT shares can, subject to certain conditions being satisfied, be used to defer a tax gain realised on a non-VCT asset when the gain is, effectively, reinvested in VCT shares. Following the introduction in the UK Finance Act 1998 of

\footnotetext{
${ }^{3}$ In general, financial institutions dominate the ownership of UK quoted companies. As at 31 December 2001 UK taxexempt pension funds held $16 \%$ of the market value of the London Stock Exchange and UK insurance companies whose business also includes tax-exempt pension funds held a further 32\%. The largest shareholding group was nonUK institutions and individuals, which held 50\% (Office of National Statistics, 2002).

${ }^{4}$ After allowing a three-year period in which to identify and appraise potential investments, at least $70 \%$ of the VCT's investments must comprise new issues in unquoted trading companies. Of this $70 \%$, at least $30 \%$ must be in the form of equity, and the balance may be preference or debt capital.

${ }^{5}$ In an attempt to ensure a diversified portfolio, no single holding may exceed $15 \%$ of the VCT's investments.

${ }^{6}$ In order to target investment at small, unquoted funds, there is an upper limit on the size of companies in which VCTs may invest. Immediately prior to investment by the VCT, the gross assets of the investment target company must not exceed $£ 15 \mathrm{~m}$; and immediately after, they may not exceed $£ 16 \mathrm{~m}$ (prior to $6^{\text {th }}$ April 1998 the corresponding figures were $£ 10 \mathrm{~m}$ and $£ 11 \mathrm{~m}$ ).

7 Discussions with VCT managers indicate, however, that VCT investors rarely consider exit strategy options at the time of initial subscription. This view is consistent with the findings reported in PACEC (2003).

${ }^{8}$ Liquidity could also be provided under general powers available to all limited companies (S.163, Companies Act 1985) to make market purchases or buy-backs of their own shares. All of the eighteen VCTs focused upon in Table 4 (see subsequent discussion) have adopted such powers. The terms of the permitted buy-backs, based on a review of the buy-back terms of ten of the eighteen VCTs, indicates that the maximum price permitted is based on $105 \%$ of midmarket price (6 VCTS) or the lower of $105 \%$ of the mid-market price and net asset value (4 VCTs). Clearly, under both mechanisms of price determination, the conditional form of the investment relief will still create a lock-in effect although taking a mid-market price reduces its magnitude.
} 
taper relief (for capital gains tax calculation purposes), the ability to defer a gain is now of less significance to potential investors - particularly in relation to gains on business assets. ${ }^{9}$

Further relief is given by an exemption from capital gains tax in respect of any gain on disposal of shares in VCTs, and by exemption from income tax upon dividends received from VCTs. For the purpose of this paper, these two reliefs are together referred to as 'return reliefs'. The return reliefs are available to all individual UK tax paying shareholders ${ }^{10}$, irrespective of whether they acquired their shareholding by direct subscription or by purchase in the subsequent secondary market.

Therefore, in subscribing for shares in a VCT an investor is acquiring four distinct assets or rights: (i) a share of the VCT's net assets; (ii) the right to investment relief; (iii) the possibility of roll-over relief; and (iv) the right to return reliefs. Of these, the second and third cannot be acquired by a secondary market purchaser.

Since a subscriber forfeits the right to investment relief upon selling VCT shares within the required holding period, and since investment relief may not be transferred to purchasers in the secondary market, we deduce that the secondary market in a VCT share will be characterised by high bid-ask spread and low trading volume during the required holding period for that share. A market maker will only offer to sell VCT shares for a price at which he / she can readily obtain (or replace) such shares in the market: this price will include, to some extent, an element reflecting the value of investment relief rights of original subscribers. Potential purchasers, by contrast, will place no value on investment relief and will not be prepared to pay for it. Once the required holding period for the share is over, we may expect to see a lower bid-offer spread and consequently higher trading volume.

We would expect, therefore, that the quoted prices for VCTs in the secondary market to comprise the following elements: market value of underlying VCT assets; conventional discount (or premium) upon the market value of underlying assets, as per the literature on investment trusts in general; expected value of return reliefs; conventional marker makers' spread; and spread attributable to the expected value of investment reliefs.

As at $6^{\text {th }}$ April 2002, sixty-eight VCTs had been listed on the LSE Twelve of these had more than one class of share, thus giving a total of eighty VCT quotations. ${ }^{11}$ Table 1 analyses this population by year of issue.

\footnotetext{
${ }^{9}$ In his budget speech, the Chancellor of the Exchequer announced on $17^{\text {th }}$ March 2004 a series of changes to the nature of the tax incentives. For shares issued on or after 6 April 2004 the rate of income tax relief for investments was to be increased from $20 \%$ to $40 \%$; capital gains tax deferral relief was no longer available for gains reinvested in VCT; and the annual taxpayer VCT investment limits was raised from $£ 100,000$ to $£ 200,000$. These changes recognised the primacy of income tax related reliefs over gain deferral or roll over relief.

${ }^{10}$ Subject originally to an upper investment limit of $£ 100,000$ per fiscal year per individual, later raised (see previous footnote).

${ }^{11}$ The use of multiple classes is designed to avoid value dilution on subsequent issues. For example, Foresight Technology VCT plc has two categories of ordinary share. The company maintains and disclosures a separate balance sheet and income statement relating to each category, thereby permitting their separate and independent valuation.
} 
The apparent importance of the tax benefits to shareholders is evidenced in that 32 of the flotations occurred in either March or April, late in the fiscal year - reducing uncertainty over individuals' tax positions and marginal tax rates, and also minimising financing costs. Based on a survey of 496 VCT investors, 'the single most attractive feature' of the scheme is the income tax relief based on the initial subscription ( $41 \%$ of investors) followed by the CGT deferral (23\% of investors); whereas the income tax exemption on dividends and the CGT exemption on disposal of shares in VCTs where described as 'the single most attractive feature' of VCTs by $4 \%$ and $18 \%$ of investors respectively (PACEC, 2003).

\section{Valuation of VCT investment relief}

We turn now to the formulation of a theoretical model for valuation of investment relief. Consider an individual investor, UK resident for taxation purposes, who subscribes amount $I$ in a VCT at time $t_{0}$ during fiscal year $F Y_{0}$, on which amount he / she expects income tax relief at rate $T_{0}$

The value of investment relief is not certain to the investor until the end of the required holding period since, for example, the investor's circumstances may change and he or she may become a distressed seller. Suppose that:

(i) the risk free rate is $f$ per time period

(ii) personal taxation payable in respect of fiscal year $F Y_{i}$ is due at time $t_{i}$ (in the UK, personal taxation is payable by $31^{\text {st }}$ January following the fiscal year to which the tax relates)

(iii) the rate of interest upon tax 'clawed back' in respect of tax reliefs previously enjoyed but, retrospectively, no longer allowable is $c$ per period (simple interest, as under tax legislation) and

(iv) the rate per period which represents discount rate for risk appropriate to investment relief is $r$

The cash flow benefit of investment relief is, therefore, $I T_{0}$, to be enjoyed at time $t_{0}$. The value of this investment relief to the investor in the period before he / she receives the cash flow benefit is the expected benefit appropriately discounted. In the period after receiving the cash flow benefit, but whilst still within the required holding period, the value is the potential liability for overdue tax (i.e., the cash outflow which will be suffered should the VCT holding be sold ${ }^{12}$. Once beyond this holding period, the value disappears.

The VCT subscriber, however, might divest the holding (or part thereof) before the end of the required holding period for a price which is below the original subscription price. In such a case the 'clawback' of investment relief is restricted to divestment proceeds at the income tax relief rate previously enjoyed, plus

\footnotetext{
${ }^{12}$ We assume rationality in the repayment of overdue tax, that is, given the usual level of clawback interest rate in comparison to expected risk adjusted asset returns, that overdue tax will be paid immediately a liability is recognised.
} 
interest. So in the period between point of cash flow benefit and end of the required holding period, the valuation of investment relief is not based, necessarily, on the amount originally invested, $I$; but, rather, on the lesser of this and the bid price, $P_{b i d}$, at the time of divestment; that is, on $\min \left(I, P_{b i d}\right)$.

More formally, the value of investment relief, which we denote $V I R$, is as follows over three periods (period from point of investment up to point of cash flow benefit; period between point of cash flow benefit and end of the required holding period; and period from end of the required holding period):

$$
V I R=\left\{\begin{array}{ll}
\frac{I T_{o}}{(1+f)^{\left\{t_{0}^{\prime}-t\right\}}(1+r)^{\left\{t_{0}+N Y-t\right\}}} & \text { for } t \leq t_{0}^{\prime^{\prime}} \\
\min \left(I, P_{b i d}\right) \frac{T_{o}\left(1+c\left\{t-t_{o}^{\prime}\right\}\right)}{(1+r)^{\left\{t_{0}+N Y-t\right\}}} & \text { for } t_{0}{ }_{0}<t<t_{o}+N Y \\
0 & \text { for } t \geq t_{0}+N Y
\end{array}\right\}
$$

where $\{b-a\}$ represents the number of discounting / compounding periods from time point $a$ to time point $b$; $Y$ represents the number of discounting / compounding periods in a year; and $N$ represents the length in years of the required holding period. Notice that in the period prior to $t^{\prime}{ }_{0}$ no adjustment is made in respect of restricted clawback, since there is a zero assumed clawback during this period (the investor is assumed not to have claimed / enjoyed the cash benefit of investment relief). This leads to the profile of investment relief valuation over time as shown in Figure 1 (which figure, for simplicity of profile, assumes that the bid price is always in excess of or equal to the initial subscription price).

\section{*** insert Figure 1 about here $* * *$}

We now consider what the proceeds of sale are likely to be in the context of market maker's bid or offer prices. The 'standard market maker's spread' covers the market maker's transactions costs, adjustment for operational risk, normal profits, etc. The market maker must post bid and offer prices at which it is prepared to trade. Faced with a buy order, the market maker must obtain shares and cannot, in the normal course, rely upon finding a financially distressed seller willing to part with his VCT shares without being recompensed for the value of investment relief. Therefore the offer (as relative to the bid) price will include not only standard market maker's spread, but also a valuation of investment relief. Conversely, the market makers bid price reflects that fact that he anticipates selling VCT shares onwards on the secondary market to an investor who will not be able to enjoy, and therefore does not value, investment relief.

The valuation of market maker's bid / offer spread (which we can observe) follows from the above as: 
A further impactor upon the theoretical model might be the valuation of roll-over relief available to VCT subscribers. This may also be valued, along with investment relief, within overall market maker's spread, and abstracting from this may mean that model (2) under-estimates market maker's bid / offer spread. Rollover relief value is, however, highly investor-specific and difficult to estimate. It is also likely to be at least an order of magnitude lower than the value of investment relief (being the discount rate in respect of payment deferral applied to a tax rate in turn applied to a principal sum).

\section{Data, hypotheses and methodology}

\subsection{Data set}

The determination of the data set was influenced by the public availability of the required data and the necessity for sufficient within-VCT-required-holding-period data points. For each VCT, such points commence approximately ten months after the end of the tax year in which the VCT is established.

The entire population of VCTs which had been listed up to $5^{\text {th }}$ April 2002 was extracted from the Primary Market Fact Sheet published monthly by the London Stock Exchange, double-checked against the TrustNet database. After excluding the twelve VCTs with multiple classes of shares (see footnote eleven and Table 1) this led to a sample of sixty-five. The $5^{\text {th }}$ April 2002 cut off date ensures that, for every VCT in the sample, there at least are two years of trading after its associated $31^{\text {st }}$ January investment relief cash flow benefit date.

For each VCT in the sample, all available Datastream daily data from $5^{\text {th }}$ August 1994 to $18^{\text {th }}$ March 2005 for market maker's ask price (Datastream item $P A$ ) and market maker’s bid price $(P B)$ was extracted. In addition, for each sample VCT, daily number of customer bargains and daily number of shares traded in customer bargains over the same period were obtained direct from London Stock Exchange, through bespoke interrogation of LSE databases by LSE staff. $^{13}$

Although VCTs have a number of unique characteristics, there are some financial instruments which invest in similar areas and are listed. Two comparator samples of listed investment trust stocks were selected by searching the TrustNet database: searching for 'UK Venture / Development Capital' investment trusts yielded 13 trusts; and searching for 'UK Equity Growth' investment trusts yielded 29 trusts. All available daily data items as above were collected for these comparator samples.

\footnotetext{
${ }^{13}$ Datastream data was collected on $18^{\text {th }}$ March 2005. Collection of data up to this date ensured at least two years of data points within the required holding period of each sample VCT: the required holding period would have commenced $31^{\text {st }}$ January 2003 for the most recently established VCT in the sample. In view of Datastream's decision not to collect data on number of customer bargains and number of shares traded therein from $27^{\text {th }}$ March 2002, it was necessary to complete the collection of the required data set by purchasing the volume data directly from the London Stock Exchange. As regards the VCT sample, a significant change to the VCT tax relief relating to capital gains tax deferral effective VCTs issues made on or after $6^{\text {th }}$ April 2004 cautions against the inclusion of later-incepted VCTs in the sample.
} 
For each sample VCT, its subscription date was established from the LSE Primary Market Fact Sheets and the date of the end of the required holding period deduced. Where multiple allocations of a single VCT share class were made, the date of the first was taken as the subscription date in order to maintain an assumption that market makers are rational and would not wish to under value the spread. In practice further allocations of a single VCT share class involved a relatively small number of shares. All VCTs in the sample were subscribed and allotted at a price of 100p per share.

For each sample VCT and comparator, the price spread was calculated for each day upon which bid $\left(\mathrm{PB}_{t}\right)$ and ask price $\left(\mathrm{PA}_{t}\right)$ data was collected:

$$
S P R E A D_{t}=P A_{t}-P B_{t}
$$

\subsection{Hypotheses}

The special taxation treatments associated with VCTs, and the $6^{\text {th }}$ April 2000 non-retrospective reduction in required holding period from five years, provide a context in which we may formulate and test hypotheses concerning the impact of tax considerations on valuation and market behaviour. The null hypothesis in each case is one of no such impact.

Given valuation of investment relief by initial subscribers, we hypothesise as follows:

Hypothesis A: The bid-offer spread of VCTs within the required holding period is higher than that for conventional investment trusts.

Since investment relief is forfeit if a subscriber sells their VCT holding within the required holding period, and trades in this period are, therefore, likely to be infrequent:

Hypothesis B: The volume of VCT shares traded within the required holding period is lower than that for conventional investment trusts.

Since investment relief is certain for the subscriber as from the end of the required holding period:

Hypothesis C: The bid-offer spread of VCTs falls immediately at the end of the required holding period, and remains at lower levels thereafter.

From our modelling in the previous section, and focussing upon the magnitude (rather than merely the existence) of a pricing effect: 
Hypothesis D: The bid-offer spread of VCTs includes a valuation of investment relief which is characterised by the theoretical modelling in the previous section.

The value of investment relief, in the traditional asset valuation paradigm, is driven by future expectations and perceived risk. Therefore, given a shorter required holding period, ceteris paribus, the valuation of investment relief during the early life of a VCT will be higher:

Hypothesis E: The bid-offer spread over the early life of VCTs subscribed prior to the reduction in required holding period is less than the bid-offer spread over corresponding periods in the lives of VCTs subscribed after the reduction.

\subsection{Methodology}

We consider in more detail descriptive statistics upon spread and volume data for our samples, segmented in various ways, and undertake comparison of means between various sub-samples. This includes descriptive statistics and comparable estimates for our comparator samples: although we may not assume that the comparators provide a perfect control, they are sufficient for the rather limited objective of comparing the general size of spreads and the amount of trading activity.

We then undertake regression analysis aiming to model SPREAD, subsuming valuation of investment relief per our theoretical model. The objective of this analysis is to examine whether or not VCT spread evolves over the course of the required holding period in the manner anticipated and also whether or not the spread for VCTs is influenced by other factors in a manner similar to that for other stocks / investment vehicles. This section now continues with discussion of development of our sample for regression purposes and of development of a reasonable, estimable regression model.

The value of investment relief variable VIR was computed by reference to the model developed in the previous. This describes the theoretical valuation of the investment relief, including adjustments for the rate of interest applied on overdue (clawed-back) tax.

We must account also for other factors which may further affect the bid-ask spread. Stoll (1989) decomposes the spread on stocks into three factors - those related to adverse information, to the costs of holding inventory and to costs of processing orders. This is corroborated by Glosten (1987), who decomposes the spread into portions attributable to information asymmetry and 'other' elements (encompassing the factors of Stoll). Our estimates more closely follow the approach of Atkins and Dyl (1997), who do not include an adverse information effect in their estimates of the spread. The existence of and ability to exploit informational advantages in VCTs is theorised to be relatively small. The directors of the VCT may be in a position to exploit informational advantages being better aware of the holdings of the 
VCT - directors' stockholdings are, however, typically very small and change only very rarely ${ }^{14}$. We therefore include only factors related to inventory and processing costs in the empirical model.

Atkins and Dyl (1997) model spread as:

$$
\operatorname{SPREAD} D_{t}=\alpha+\beta_{1} M V A L_{t}+\beta_{2} V R E T_{t}+\varepsilon_{t}
$$

where $M V A L$ represents market value, VRET represents the variance of returns and $\mathcal{E}$ is a stochastic error term. ${ }^{15}$

The greater the market value of the firm, the greater the assumed depth of the market and, consequently, the lower the inventory costs. Consequently the expected sign on the coefficient $\beta_{1}$ is negative. The higher the variance of returns the higher the risk associated with holding the stock and the greater the inventory costs. Therefore, the expected sign on coefficient $\beta_{2}$ is positive.

This model needs adaptation for our purposes because few VCTs are particularly large and the depth of the market is expected to change more with the performance of the VCT since inception than with the market value of the firm. The increased flows into high performing managed funds are well documented in the literature (see, for example Sirri and Tufano (1998)). Therefore, price is taken as a proxy for willingness to buy and hence the depth of the market. The variance of the stock over the previous 30 days is included as a measure of inventory costs, after Atkins and Dyl. Where available in our data set, other measures of market depth are included in the form of the number and volume of customer bargains in the previous 30 days. This gives an estimable model as follows:

$$
S P R E A D_{t}=\alpha+\beta_{1} V I R_{t}+\beta_{2} P B_{t}+\beta_{3} V B_{t}+\beta_{4} B A R_{t}+\beta_{5} V O L_{t}+\varepsilon_{t}
$$

where VIR represents the valuation effect of investment relief based upon our theoretical model; $P B$ bid price; $V B$ variance of the bid price over the previous 30 days (i.e., $t$-30 to $t-1$ ); $B A R$ the number of customer bargains over the previous 30 days; and $V O L$ the number of shares traded in customer bargains over the previous 30 days.

$V I R$ is calculated from expression (1) with the following assumptions and substitutions: $t_{i}{ }_{i}$ in respect of any fiscal year $F Y_{i}$ is $31^{\text {st }}$ January in the fiscal year immediately following (this being the due date for personal taxation in the UK, and the rational payment date for tax payers in a net payment position); $T_{i}$ is $20 \%$ for all relevant fiscal years, as per VCT taxation regulation; $c$ over relevant periods is as obtained from HM Revenue and Customs; and discount rate $r=4 \%$ p.a.

\footnotetext{
${ }^{14}$ Source: Various VCT annual reports.

${ }^{15}$ They also include an identifying variable in order to run a second stage model of the holding period which is not included here.
} 
In this model, the expected sign of the VIR coefficient is positive, and that of the $P B$ coefficient is negative. There is no firm sign expectation concerning the coefficient of $V B$ : although increasing levels of variability are generally associated with increased inventory costs and, therefore, higher spreads, they might indicate a more active market and a resulting decrease in required spread. Neither are there firm expectations concerning the coefficients of $B A R$ and $V O L$ : increases in these variables are normally associated with increasing depth of market and, thus, decreasing spread, but, in the particular context of this paper, the occurrence of trades might stimulate market makers to increase spread.

Before estimation of the regression, we must be satisfied as to the time series properties of the variables. Many financial time series follow a random walk (or test as such) and this may be true of the $P B$ variable. If market makers set the spread as a percentage of the bid price, then the SPREAD variable itself might also be non-stationary. To evaluate the possibility that the variables are non-stationary, their time series were plotted and inspected; and Augmented Dickey-Fuller (ADF) tests were conducted for all the SPREAD time series and for all other series where the times series plots suggested non-stationarity. ${ }^{16}$ As expected, there were many cases where the bid price appeared to be of order of integration one (I(1)) and tested as such. There were also a few cases where the spread tested as I(1) as well. Fortunately, the solution in this context is relatively straightforward, since we are principally interested in the behaviour of the spread over the required holding period and so a short-run model is feasible. Therefore, we translated the regression model to be estimated in first differences, without affecting the interpretability and the expected signs of estimated coefficients:

$$
\triangle S P R E A D_{t}=\alpha+\beta_{1} \Delta V I R_{t}+\beta_{2} \Delta P B_{t}+\beta_{3} \Delta V B_{t}+\beta_{4} \Delta B A R_{t}+\beta_{5} \Delta V O L_{t}+\varepsilon_{t}
$$

As discussed above, the VCT secondary market is relatively illiquid and this is reflected in a low level of variation is the spread of a number of VCTs. In order to have sufficient variation in the dependent variable the initial regression analysis excludes VCTs with less than 30 changes in the spread resulting in a reduced sample of eighteen VCTs. An examination of these eighteen VCTs suggests systematic differences with the remainder. In particular, the eighteen more active VCTs have a greater number of market makers registered to trade them when compared to the remainder ${ }^{17}$ The direction of the causality between the higher number of market makers and the higher variation in the spread is an empirical question.

We pool the eighteen 'active' VCTs to produce a panel comprising 18 cross sectional units and 801 time series observations, resulting in a data set comprising 14,418 data points. A benefit of pooling is improved efficiency by using data with increased variability (Kennedy, 2003). As the number of cross sectional units is small relative to the number of time series observations, it is inappropriate to use conventional fixed or

\footnotetext{
${ }^{16}$ See Enders (1995) for a discussion of the ADF test and appropriate responses where series test as non-stationary.

${ }^{17}$ With three exceptions, the eighteen 'active' VCTs have as least two market makers - with four VCTs having three market makers. Of the other 47 VCTs, 24 had a single registered market maker, the reminder two or more. The difference in the proportion of VCTs with multiple market makers as between the eighteen active VCTs and the remaining 47 VCTs is significant at the $1 \%$ level, $\chi^{2}$-stat. $=-6.341(1)$.
} 
random effect models (Kennedy, 2003). Instead we employ a feasible generalised least squares (FGLS) estimator (Greene, 2000). As diagnostic tests indicate significant autocorrelation and heteroskedasticity using Durbin-Watson and Breusch Pagan test statistics respectively, the FGLS estimator employed allows for group-wise heteroskedasticity and within-group autocorrelation. Given the usual criticisms of FGLS, in particular having to estimate unknown error structure, we also estimate using panel corrected standard error (PCSE) estimates (Beck and Katz, 1995). To assess the sensitivity of the results to the choice of the FGLS and PCSE estimators, we also report results based on a conventional fixed effects model (FEM). Therefore three sets of results are reported for the sample of eighteen VCTs. As a test of the robustness of the results we also report the FEM when estimated on the full sample of sixty five VCTs. ${ }^{18}$

\section{Results}

\subsection{Descriptive statistics and comparisons}

Panel A of Table 2 gives summary statistics upon the mean value of the SPREAD variable for our VCT and comparator samples. ${ }^{19}$ The statistics are segmented between 'all periods', then 'prior to end of required holding period' and 'after end of required holding period' (the last two being pertinent only to the VCT sample). Panels B and C of Table 2 follow with descriptive statistics upon the mean value of SPREAD as a percentage of bid price, and mean number of customer bargains per day. Table 3 shows the results of pertinent comparison-of-mean tests.

\section{*** insert Table 2 about here $* * *$}

The mean absolute spread for all VCTs with a five-year required holding period is 18.956 pence, with daily spread ranging between 1 and 550 pence. By contrast, and in line with expectations under hypotheses $A$ and $D$, the UK venture / development investment trust sector has a smaller mean spread of 9.602 pence over the same period. For UK growth investment trusts, the spread is smaller still, as is the standard deviation and range. Since there are rather more growth than venture / development investment trusts within our sample, combining the comparator samples results in statistics more closely resembling growth investment trusts.

We expect the spread on VCTs to be larger during the required holding period (as compared to beyond it), in line with hypotheses $C$ and $D$, and this confirmed by the lower half of Table 2, Panel A where the mean spreads post required holding period for VCTs with five-year and three-year required holding periods are, respectively, 12.277 pence and 12.910 pence; compared with 20.637 pence and 19.387 pence respectively during required holing period.. Our theoretical model also suggests that the VCTs with a threeyear required holding period are, ceteris paribus, likely to have a higher spread than those VCTs with a five-

\footnotetext{
${ }^{18}$ The FGLS and PCSE estimators require a balanced panel and are estimated over 801 observations per VCT, this being the shortest time series of the 18 VCTS. It is not possible to use these estimators on the full sample / population as the number of observations per VCT is not constant given their varying start dates.

${ }^{19}$ All of the VCTs in our sample were issued at a price of 100p per share.
} 
year required holding period ${ }^{20}$. This, hypothesis $E$, however, is not confirmed by a mean spread within required holding period of 19.387 pence for VCTs with a three-year required holding period compared to 20.637 pence for VCTs with a five-year required holding period.

The price of our trusts are not constant over the sample period and this might naturally raise the concern that an interpretation of any differences in the absolute spreads will be misleading where market makers set spreads with regard, to some extent or other, of percentage of instrument value. Therefore, descriptive statistics upon spreads as a percentage of bid price are calculated and presented in Panel B of Table 2. Very similar conclusions may be drawn from this panel as are drawn from Panel A: we note that the spreads for VCTs are considerably larger than those for our comparator samples (consistent with hypotheses $A$ and $D$ ); and that the spread for VCTs falls when the end of their required holding period is reached (consistent with hypotheses $C$ and $D$ ). Here, however, consistent with the prediction of hypothesis $E$, spread as a percentage of bid price during the required holding period is seen to be greater for VCTs with three-year required holding periods than it is for those with five-year required holding periods.

A further topic of interest is whether the volume of trading is relatively small for VCTs within their holding period as compared with after and in comparison to more conventional instruments. Customer bargains per day are chosen as the basis for analysis since we are interested in the influence of tax effects on individuals' decisions (and including market maker bargains would not provide a basis on which to compare the effects of changing tax liability on private shareholders). Table 2, Panel $\mathrm{C}$ is in line with expectations and hypothesis $B$ : VCTs are very thinly traded during their required holding period, in comparison to VCTs beyond their required holding period and, most markedly, in comparison to our comparator investment trusts. Albeit the data upon comparator samples in this respect is not fully controlled (for, e.g., number of units in issue or value), the results are, we submit, stark and compelling.

Table 3 presents the results of formal tests of the difference between the means as discussed above. All differences are of the hypothesised sign, with one exception, and are significant at the $1 \%$ level. A commentary upon some of the key comparisons follows.

\section{*** insert Table 3 about here $* * *$}

The second and third rows of Table 3, Panel A present tests of whether the spread for VCTs falls when their five-year or three-year required holding period ends. The differences of 8.361 pence and 6.477 pence are both of the expected sign and statistically significant at a $1 \%$ level. Following the discussion of the statistics in Table 2, comparison of VCTs and our other sampled trusts is more appropriate if undertaken for percentage as opposed to absolute spreads. Table 3, Panel B therefore presents a comparison of the mean percentage spreads. In the first row of Panel B, we see that the VCTs within a three-year required holding period have a significantly higher mean percentage spread than those with a five-year required holding

\footnotetext{
${ }^{20}$ Many more VCTs came close to or reached the end of their five-year required holding period than was the case for those with a three-year term. Since we expect the spread to be greater as the end of the holding period is reached, this comparison biases against finding a difference in the spread for the different types of VCT.
} 
period (the corresponding relationship not having been found in absolute spreads, however, in the first row of Panel A). We see in the second and third rows of Table 3, Panel B that percentage spread for VCTs falls when their five-year or three-year required holding period ends (in confirmation of the findings from Panel A, again significant at the $1 \%$ level in each case).

Since the percentage spreads on our two comparator samples are only marginally different (see Table 2, Panel B), we select the combined comparator sample as a basis for comparison with VCT percentage spreads in Table 3, Panel B. In each comparison, the percentage spread on VCTs is significantly greater than that of the comparators. This finding in isolation may indicate merely that the spread on VCTs is greater than that on more conventional investment trusts because the market is thinner, irrespective of whether the required holding period has ended (and, therefore, market makers require a greater spread to cover higher inventory costs). This possibility is controlled for in our regression analysis (see below).

Panel C of Table 3 provides results of comparisons of number VCT customer bargain per day before versus after the end of their required holding periods; and between VCTs and comparators. Although the mean number of VCT customer bargains is relatively small both before and after the end of their required holding periods, the number per day after the end of the required holding periods is about three times the number observed before the end of the required holding periods (difference statistically significant at the 1\% level). Trading in VCTs is markedly thinner than in the comparator samples, significant at the $1 \%$ level, albeit this result is subject to foregoing caveats.

\subsection{Regression estimations}

An earlier section discusses the development of the empirical model. The empirical model (6) was estimated for the period from supposed cash benefit of investment relief until end of required holding period - that is, for $t^{\prime}{ }_{0}<t<t_{o}+N Y$, i.e., the 'middle section' of our model - using FGLS, PCSE and FEM estimation techniques. The estimation results are summarised in Table 4.

\section{*** insert Table 4 about here $* * *$}

Each of the estimated models is significant, as indicated by the statistically significant log-likelihood functions in the case of FGLS and PCSE, and the F-statistic in relation to the FEM. When the FEM model is estimated over the population of VCTs the adjusted $R^{2}$ of $3.8 \%$ is far lower than the corresponding value of 48.9\% when the estimation is performed using the sample of eighteen VCTs. This fall is to be expected because of the inclusion of additional VCTs with extremely low levels of variation in spread, one of the dependent variables.

Considering the variable $\Delta V I R$, in each of the three estimations based on the sample of eighteen VCTs the estimated coefficient was significantly greater than zero and close to the expected value of one. A similar result arises when the FEM estimation is based on the population. Therefore, there is strong support for the 
hypothesis $D$, which is robust to variation in the method of estimation method and the changes in the sample composition. In all four estimations, the coefficient on $\triangle P B$ has the expected negative sign although in two cases, PCSE and FEM, the coefficient is not statistically significant at the 5\% level.

The estimated coefficients relating to variance in bid price $(\Delta V B)$ are generally consistent, being negative in three estimations out of four, but insignificantly different from zero in all cases. As regards the coefficients of the trading volume variables, the estimated coefficients of $\triangle B A R$ are consistently positive across all four estimations, although are significantly different from zero (at the $2.5 \%$ level) only in the cases of the PCSE and FEM(65) estimations; and the estimated coefficients of $\triangle V O L$ are completely consistent, being positive yet insignificant across all four estimations. Comment in sub-section 4.3 (above) concerning the non-predictability of the sign of the coefficients of the variance and volume variables in the current setting pertains.

Spread does, therefore, evolve over time in the way that we expected as per hypothesis $D$; and there is evidence that VCT spread responds to factors such as price and volatility in a similar fashion to other instruments. In general these results confirm that tax effects are priced into the spread and that price and trading behaviour in the VCT market conforms to theory and associated expectations.

\section{Conclusion}

This paper documents theoretical and empirical evidence of a lock-in effect arising from the conditional nature of tax incentives provided to increase demand for Venture Capital Trust IPOs. In particular, VCT bidask spreads evolve over time in a way that is consistent with investment relief being valued in the share price by the shareholder during the required holding period (after the end of which the spread falls significantly). Consistent with the influence of the required holding period on investor behaviour, the number of customer bargains is minimal during this period and increases significantly thereafter. Spread is greater for VCTs with a three as opposed to five-year required holding period. Further, although there are potential non-tax explanations, there is evidence that VCT spread is greater than and trading volume less than that for comparable non-VCT investment vehicles. Circumstantial evidence in the form of buy backs is also consistent with the presence of a lock-in effect.

This study is novel in that the magnitude of the lock-in effect can be calculated with certainty without requiring access to confidential shareholder information. In addition, a further methodological opportunity is provided by an unexpected change in related taxation legislation (as regards length of required holding period).

Our results lead to a questioning of the benefit of requiring VCTs to be listed companies. This is reinforced by the relatively low importance attached to exit strategy concerns by VCT shareholders at the time of subscribing. Although a listing may bring benefits such as increased monitoring - leading to reduced 
agency costs between managers and shareholders - an interesting issue is whether this benefit exceeds the direct and indirect costs associated with obtaining and maintaining a full market listing.

\section{References}

Atkins, A.B. and Dyl, E.A. (1997). 'Transactions Costs and Holding Periods for Common Stocks'. Journal of Finance, 52(1) (March): 309-325.

Beck, N. and Katz, J.N. (1995). 'What to do (and not to do) with time series cross-section data'. American Political Science Review, 89(3): 634-647.

Blouin, J.L., Raedy, J.S. and Shackelford, D.A. (2002). 'Equity Price Pressure from the 1998 Reduction in the Capital Gains Holding Period'. The Journal of the American Taxation Association, 23(supplement): 70-93.

Collins, J. and Kemsley, D. (2000). 'Capital Gains and dividend capitalisation in firm valuation: Evidence of triple taxation'. The Accounting Review 75: 405-427.

Dhaliwal, D., Erickson, M., Frank, M.M. and Banyi, M. (2003). 'Are shareholder dividend taxes on corporate retained earnings impounded in equity prices? Additional evidence and analysis'. Journal of Accounting and Economics, 35: 179-200.

Enders, W. (1995). Applied Econometric Time Series. Wiley.

Glosten, L.R. (1987). 'Components of the Bid-Ask Spread and the Statistical Properties of Transaction Prices'. Journal of Finance, 42(5) (December): 1293-1307.

Greene, W.H. (2000), Econometric Analysis. Prentice Hall.

Guenther, D.A. and Willenborg, M. (1999). 'Capital gains tax rates and the cost of capital for small business: evidence from the IPO market’. Journal of Financial Economics, 53: 385-408.

HM Treasury (2003). Bridging the finance gap: a consultation on improving access to growth capital for small businesses. HM Treasury / HM Stationery Office 04/03 831743 (available at http://www.hmtreasury.gov.uk/media/B/E/adinvest359kb03.pdf).

HM Inland Revenue (2002). IR169 - Venture Capital Trusts - A brief Guide. HM Inland Revenue (online information available at http://www.hmrc.gov.uk/guidance/vct.htm). 
Harris, T., and Kemsley, D. (1999). 'Dividend Taxation in Firm Valuation: New Evidence.' Journal of Accounting Research, 37: 275-291.

Harris, T., Hubbard, G. and Kemsley, D. (2001) 'The Share Price Effects of Dividend Taxes and Tax Imputation Credits'. Journal of Public Economics, 79: 569-596.

Hanlon M., Myers, J.N. and Shevlin, T. (2003). 'Dividend taxes and firm valuation: a re-examination.’ Journal of Accounting and Economics, 35(2): 119-153.

Kennedy, P (2003). A Guide to Econometrics, Fifth edition. Blackwell Publishing.

Klein, P. (2001). 'The Capital Gain lock-in effect and long horizon return reversal'. Journal of Financial Economics, 59(1): 33-62.

Landsman, W.R. and Shackelford, D.S. (1995). 'The Lock-in Effect of Capital Gains Taxes: Evidence from the RJR Nabisco Leveraged Buyout’. National Tax Journal, 48(2) (June): 245-259.

Office of National Statistics (2002). Share Ownership: A report on share ownership as at $31^{\text {st }}$ December 2001. Office of National Statistics / HM Stationary Office ISSN1465-2757 (available at http://www.statistics.gov.uk/downloads/theme_economy/ShareOwnership2001.pdf).

PACEC (2003). Research into the Enterprise Investment Scheme and Venture Capital Trust - A report prepared for Inland Revenue. Cambridge U.K.: Public and Corporate Economic Consultants (PACEC) Ltd.

Reese, W. (1998). ‘Capital Gains Taxation and Stock Market Activity: Evidence from IPOs.’ Journal of Finance, 53: 1799 - 1820.

Sirri, E. R., and Tufano, P. (1998). 'Costly Search and Mutual Fund Flows'. Journal of Finance 53(5) (October): 1598-1622.

Stiglitz, J. E. (2000), Economics of the Public Sector, Third edition. London/New York: W.W. Norton \& Co.

Stoll, H. R. (1989). 'Inferring the Components of the Bid-Ask Spread: Theory and Empirical Tests.' Journal of Finance, (44)(1) (March): 115-134. 


\begin{tabular}{|c|c|c|c|}
\hline \multicolumn{4}{|c|}{$\begin{array}{l}\text { Table } 1 \\
\text { VCT issues in fiscal years 1995/96 to 2001/02 and derivation of regression sample }\end{array}$} \\
\hline Fiscal year & $\begin{array}{l}\text { Amount raised } \\
(£ m)\end{array}$ & Number of new issues & $\begin{array}{c}\text { Mean amount raised per issue } \\
(£ m)\end{array}$ \\
\hline \multicolumn{4}{|l|}{ VCTs with five-year required holding period } \\
\hline 1995-96 & 138.6 & 10 & 13.86 \\
\hline $1996-97$ & 30.2 & 4 & 7.55 \\
\hline 1997-98 & 90.0 & 8 & 11.25 \\
\hline 1998-99 & 135.9 & 7 & 19.41 \\
\hline 1999-00 & 112.3 & 8 & 14.04 \\
\hline \multicolumn{4}{|c|}{ VCTs with three-year required holding period } \\
\hline $2000-01$ & 176.9 & 15 & 11.79 \\
\hline 2001-02 & 66.4 & 13 & 5.11 \\
\hline Total & 750.3 & 65 & 11.03 \\
\hline Further issues of additional share classes & $\mathrm{n} / \mathrm{a}^{1}$ & 12 & \\
\hline Total issues & & 77 & \\
\hline
\end{tabular}

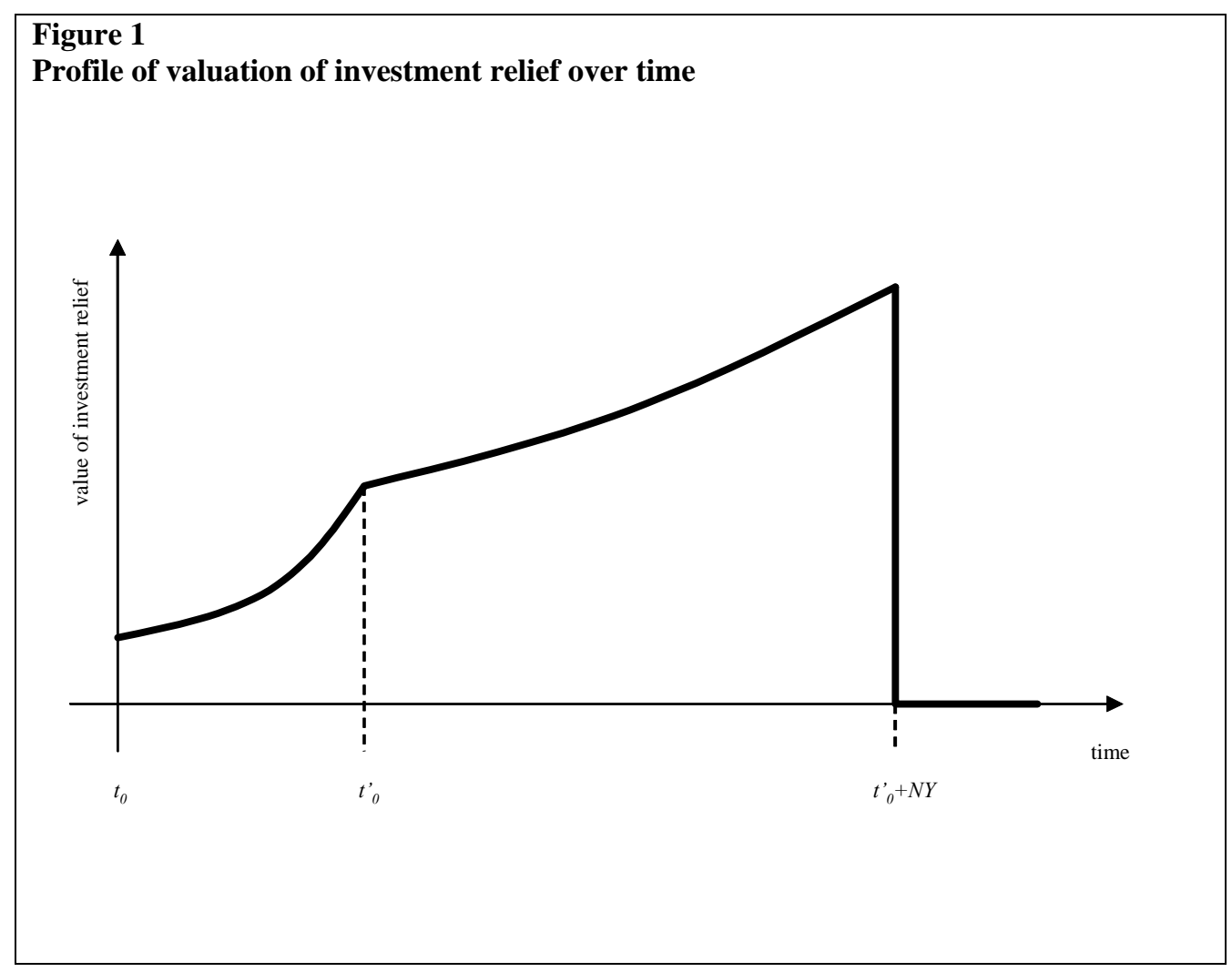




\section{Table 2 \\ Descriptive statistics}

Panel A: Mean value of SPREAD in pence

All periods

VCTs with a five-year required holding period

VCTs with a three-year required holding period Comparator sample: UK venture / development Comparator sample: UK growth

All comparators

Prior to end of required holding period

VCTs with a five-year required holding period

VCTs with a three-year required holding period

All VCTs

After end of required holding period

VCTs with a five-year required holding period

VCTs with a thee-year required holding period

All VCTs

$\begin{array}{ccccccc}51,888 & 18.956 & 25.147 & 5.579 & 63.869 & 1 & 550 \\ 29,007 & 18.036 & 14.690 & 2.259 & 8.346 & 1 & 100 \\ 30,832 & 9.602 & 15.064 & 3.106 & 10.638 & 0.2 & 145 \\ 46,856 & 5.981 & 9.103 & 3.557 & 13.536 & 0.19 & 60 \\ 77,688 & 7.418 & 11.965 & 3.624 & 15.434 & 0.19 & 145 \\ & & & & & & \\ 41,453 & 20.637 & 27.537 & 5.145 & 53.919 & 1 & 550 \\ 22,958 & 19.387 & 15.592 & 2.169 & 7.398 & 1 & 100 \\ 64,411 & 20.191 & 23.980 & 5.259 & 61.709 & 1 & 550 \\ & & & & & & \\ 10,435 & 12.277 & 8.732 & 1.432 & 2.038 & 1 & 50 \\ 6,049 & 12.910 & 8.882 & 1.045 & 0.899 & 1 & 40 \\ 16,484 & 12.509 & 8.792 & 1.284 & 1.577 & 1 & 50\end{array}$

Panel B: Mean value of SPREAD as a percentage of bid price

$\underline{\text { All periods }}$

VCTs with a five-year required holding period

VCTs with a three-year required holding period

29,007

0.2741

0.3720

5.6996

58.4584

0.0106

9

Comparator sample: UK venture / development

30,832

0.4640

6.8497

63.9911

0.0109

0.0410

0.0564

7.4489

84.7769

0.0001

6

46,856

0.0972

0.9011

17.0698

313.53

0.0007

0.905

77,688

0.0749

0.7013

21.9404

520.277

0.0004

19

19

41,453

0.2871

0.4074

5.2879

49.7217

0.0106

9

22,958

0.3318

0.5064

6.5369

55.7175

0.0145

0.4457

6.0461

$56.0617 \quad 0.0106$

6

9

10,435

0.2224

0.1588

1.4997

5.3184

0.0110

2.5

6,049

0.2465

0.2314

1.5730

1.6532

0.0109

0.8889

All VCTs

$0.8905 \quad 1.6910$

3.7140

0.1100

2.5

Panel C: Mean number of customer bargains per day

All periods

VCTs with a five-year required holding period

VCTs with a three-year required holding period

Comparator sample: UK venture / development

Comparator sample: UK growth

All comparators

Prior to end of required holding period

VCTs with a five-year required holding period

VCTs with a three-year required holding period

All VCTs

$\begin{array}{ccccccc}51,888 & 3.919 & 12.602 & 28.126 & 990.977 & 0 & 497 \\ 29,007 & 2.356 & 4.698 & 3.994 & 20.634 & 0 & 47 \\ 30,832 & 18.766 & 83.729 & 21.374 & 954.122 & 0 & 4510 \\ 46,856 & 7.495 & 14.495 & 13.816 & 442.933 & 0 & 638 \\ 77,688 & 12.303 & 56.052 & 30.842 & 2044.325 & 0 & 4510 \\ & & & & & & \\ 41,453 & 3.1022 & 13.6372 & 27.890 & 910.857 & 0 & 497 \\ 22,958 & 1.065 & 1.797 & 3.031 & 13.353 & 0 & 18 \\ 64,411 & 2.376 & 11.036 & 34.063 & 1377.24 & 0 & 497 \\ & & & & & & \\ 10,435 & 7.163 & 6.143 & 1.412 & 3.252 & 0 & 46 \\ 6,049 & 7.253 & 7.956 & 1.843 & 3.726 & 0 & 47 \\ 16,484 & 7.200 & 6.864 & 1.699 & 4.013 & 0 & 47\end{array}$

After end of required holding period

VCTs with a five-year required holding period

VCTs with a thee-year required holding period

All VCTs

$16,484 \quad 7.200$

6.864

1.699

'Mean' statistics are calculated as the mean of daily time series, the elements of the daily time series being the mean over all pertinent VCTs or investment trusts for which required data was available on the trading day concerned.

\# excludes one VCT for which there was insufficient data. 


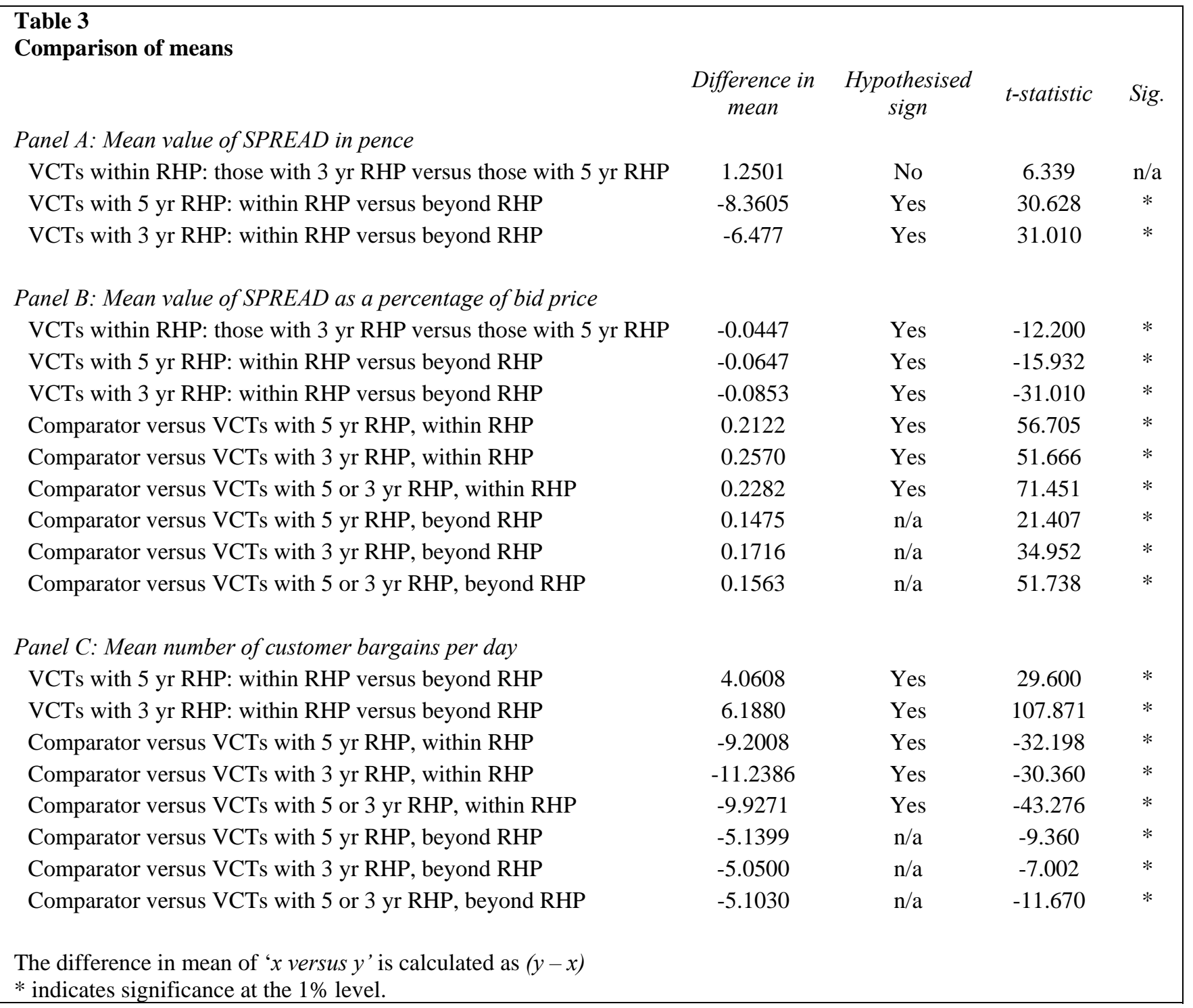




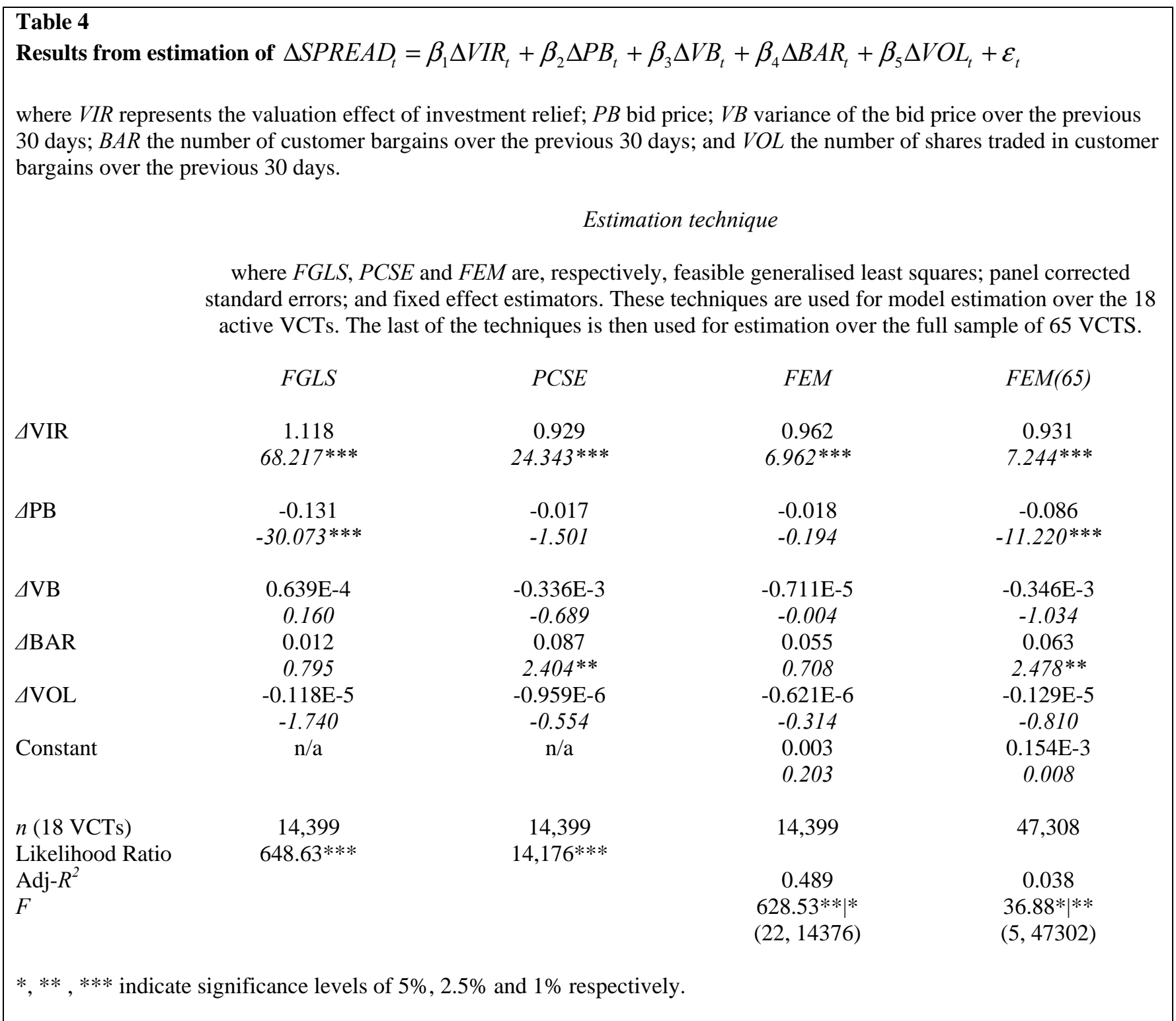

